\title{
Successful K-12 Teacher and Faculty Participation in a STEM Professional Development Program
}

\author{
George M. Nickles III, ${ }^{1}$ Carol L. Stuessy, ${ }^{2}$ \& Jane F. Schielack ${ }^{1}$ \\ ${ }^{1}$ Information Technology and Science (ITS) Center for Teaching and \\ Learning, Texas A\&M University/2Department of Teaching, Learning, and \\ Culture, Texas A\&M University
}

\begin{abstract}
The Information Technology in Science (ITS) Center for Teaching and Learning has developed an effective model for the professional development of teachers, the Learning Research Cycle (LRC), that has direct impact on K-12 teachers and their students. This paper describes the general LRC and a description of how it is applied in the ITS Center for professional development of $7^{\text {th }}$ through $12^{\text {th }}$ grade science teachers.

Data collected from participants in two cohorts of the ITS Center's summer program and from university faculty involved as resource personnel were analyzed to answer the following questions:

- How and to what extent have teachers implemented what they have learned in their summer program experience in their classrooms?

- Are there benefits to university faculty for participating in the LRC?

Data sources include participant enrollment numbers, participant demographics originally from their application records, multiple surveys of participants, records of participant research products, multiple surveys of faculty members, and personal communication. Results showed that classroom teachers effectively implemented quality classroom experiences using information technology after participation in the program. University faculty reported having a better understanding of the needs of classroom teachers and of the process of learning in general after participation in the program. Given the success of this model, the implications for implementing the LRC for engineering K-12 outreach are discussed.
\end{abstract}

\section{Introduction}

According to a report by Noeth, Cruce, and Harmston ${ }^{14}$, "[w]hile overall employment in engineering is expected to increase during the 2000-2010 period, engineering degrees over this

Proceedings of the 2005 American Society for Engineering Education Annual Conference \& Exposition 
same time period are expected to remain stable" (p. vi). Noeth et al., also note that of the high school students who took the ACT and indicated they would pursue a baccalaureate degree, those who expressed an interest in majoring in engineering consistently dropped from $8.6 \%$ in 1992 to $5.5 \%$ in 2002 . It is imperative that more K-12 students be encouraged to consider engineering as a career to not just maintain but increase the number of graduates to meet demand.

Jeffers, Safferman, and Safferman ${ }^{8}$ list many ways for engineers to reach out to K-12 students, exposing them to engineering and encouraging them to consider it as a career. These efforts include summer camps, demonstrations conducted by engineering students or professors in the K-12 classroom, and the development of teaching materials that explicitly cover engineering concepts. Many of these efforts can be found on the ASEE Engineering K-12 Center website ${ }^{2}$.

Douglas, Iversen, and Kalyandurg ${ }^{6}$ identify using specially-trained K-12 teachers as a means to improve K-12 engineering education and outreach. If teachers are trained in and understand the practice of engineering, they can both teach prepared curriculum covering engineering and independently integrate engineering into their curriculum. A significant advantage of focusing on teacher development is that all students taught by trained teachers year after year can be exposed to engineering, rather than only a select (and possibly self-selected) group of students reached with summer camps and in-class workshops. In addition, teachers can be trained in pedagogical techniques that are particularly suited to teaching engineering.

There are multiple professional development programs for K-12 teachers who want to learn more about engineering. For example, these may focus on training teachers to use pre-made teaching materials $^{7,11}$, providing lectures and demonstrations on engineering ${ }^{1,17}$, hands-on activities of engineering work, or some combination ${ }^{4,15}$. Many programs have survey data showing that teachers felt they learned a great deal from the program (e.g., ${ }^{1}$ ). One study showed through preand post-tests that teachers' content knowledge of the engineering discipline increased after going through the program ${ }^{18}$. However, there is little data on how and to what extent teachers in these programs implemented what they learned (though indicated briefly for some programs ${ }^{13,15}$ ) even though this is the main purpose of these programs, that teachers would implement what they learn. In addition, while university engineering faculty members are involved in many of these programs, there is a lack of data on what they gained from the experience.

This paper will describe a model for a professional development program called the Learning Research Cycle (LRC). This model has been developed over time by the Information Technology in Science (ITS) Center for Teaching and Learning at Texas A\&M University. The implementation of this model by the ITS Center for teacher development in science education is described. Data on teacher implementation and faculty participation is then presented with discussion. Finally, a description of how the LRC can be applied for engineering outreach to K12 teachers is given. 


\section{The Learning Research Cycle}

\section{General Description}

The Learning Research Cycle (LRC) is an innovative model of professional development engaging secondary school science teachers with scientists, mathematicians, engineers, science education researchers, and their graduate students to improve science teaching and learning through the use of information technology (IT). Professional development experiences embedded in the LRC model leverage the distributed expertise of LRC participants, who collaboratively investigate strategies for developing specialists at secondary and undergraduate levels who have deep understandings about the role of IT in doing, teaching, and learning science. In order to accomplish this goal, a collaborative professional development environment was designed to help bridge the existing "chasm" between how science is carried out in research environments and how it is taught in secondary and undergraduate classrooms ${ }^{3}$. The LRC professional development environment brings together teams of experts from university and public school classrooms and laboratories to investigate the unique aspects of this environment that affect student learning. One assumption underlying the LRC is that mathematics and science teaching and learning will be improved when all participants in a learning environment of distributed expertise (a) become more connected to the authentic science research done in field settings or laboratories and (b) work together to design innovative instructional frameworks that translate the authentic science research into learning and teaching frameworks which are implemented by participants in their classrooms.

The LRC can be called a "design artifact" (see ${ }^{9}$, p. 116), as the design arose from consolidations of "activity structures, institutions, scaffolds, and curricula" (see ${ }^{5}$, p. 6) associated with four years of ITS Center professional development activities. Aspects of the LRC include (a) embedding and integrating practitioners' authentic science learning experiences using IT, (b) challenging practitioners to use authentic scientific inquiry models of pedagogy in their own classroom settings, (c) supporting practitioners as they designed and explored their own customized classroom implementations of their authentic scientific inquiry experiences, and (d) providing a venue for disseminating more formalized classroom-based teacher research activities investigating the student outcomes associated with the use of IT-mediated authentic scientific inquiry experiences. The development of the LRC was informed by a number of artifacts, including formative assessments and surveys, results of meetings of the ITS management team, and the eventual fitting of activities, curricula, and other scaffolds into the design of a coherent model of professional development learning experiences that logically flow from one experience to another.

Figure 1 is a diagram and timeline tracing the professional development activities of participants in the LRC model through 3 summers and 2 school years of connected learning experiences. This sequence of activities was designed to enhance participants' understanding of the role of IT in doing, teaching, and learning science. These activities build on intense experiences in authentic scientific research environments that participants have with scientists in their laboratories, which occur in two three-week periods during two summers. In scientists' laboratories, participants engage in day-to-day scientific research experiences using the IT that scientists use to seek answers to scientific questions (Ia). Participants then adapt their authentic research experiences

Proceedings of the 2005 American Society for Engineering Education Annual Conference \& Exposition Copyright (C) 2005, American Society for Engineering Education 
to design similar IT-based research experiences for their students in public school science classrooms, with the assistance of science educators who also work with the participants during the same three-week period (II). At the end of the first summer, participants leave with an Instructional Framework (IF) that they integrate into their classroom instruction during the first school year (III). Reports of the results of their implementation efforts are required for participants to return for a second summer. At the beginning of the second summer, training in mentoring and fundamentals of educational research occurs for graduate students who are chosen to work as mentors for participants during the professional development activities for the second summer (IV). In July of the second summer, participants continue their work with scientists (Ib) and work with educational researchers to design classroom-based research studies to examine the effects of the IF on students learning (V). At the end of the second summer, participants leave with the expertise to test the effects of the IF on students' understanding. Participants implement their Research Plans (RP) in their classrooms during the second school year on a voluntary basis (VI) and have the option of reporting the results of their second years' implementations during a conference in the third summer (VII). Critical to the entire LRC are multiple and continuous opportunities for discourse and feedback, provided face-to-face during the summer and electronically via a community portal throughout the entire LRC (VIII).

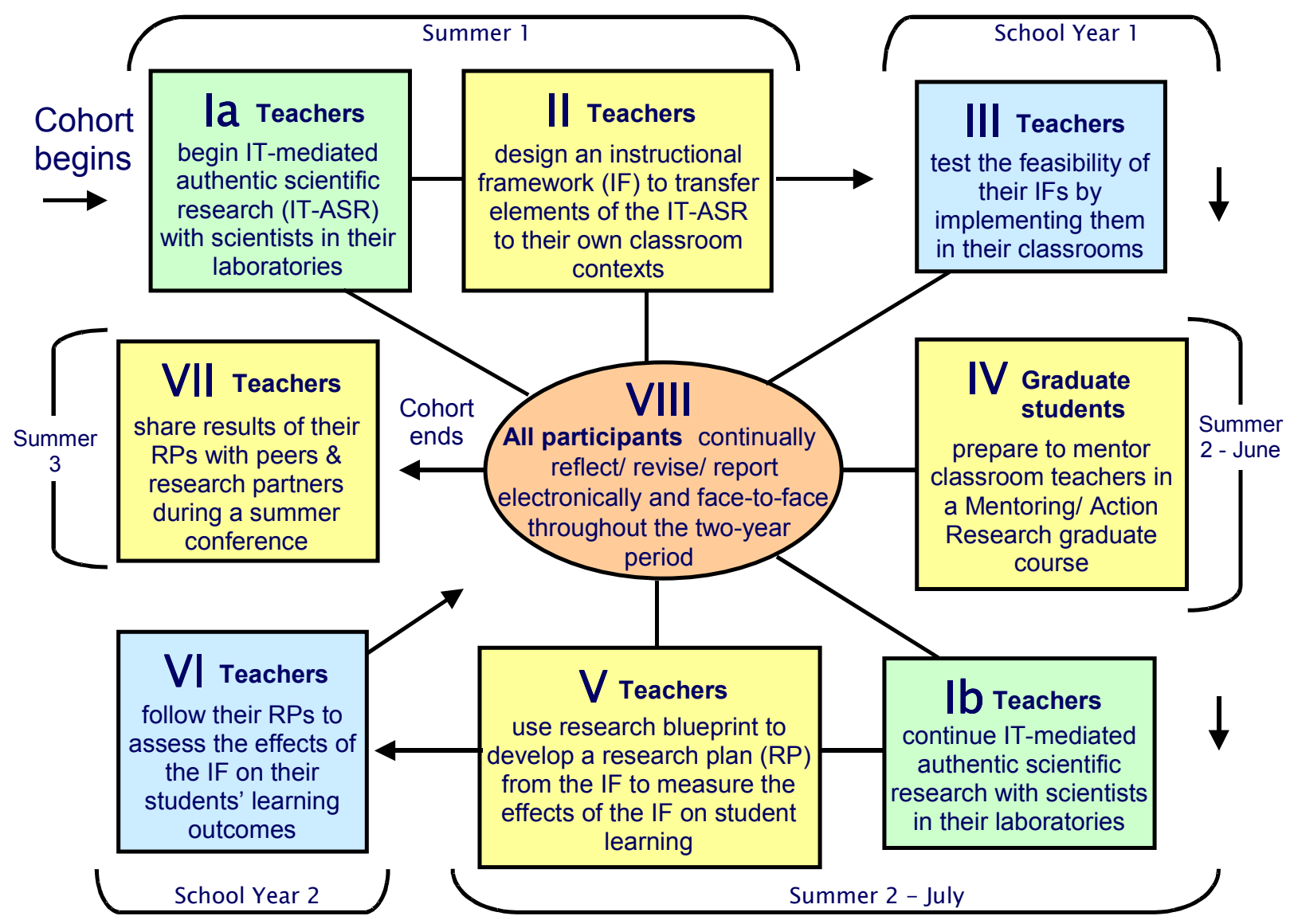

Figure 1: Timeline and Stages of the Learning Research Cycle

Proceedings of the 2005 American Society for Engineering Education Annual Conference \& Exposition Copyright (C) 2005, American Society for Engineering Education 
In the LRC model, expert research team members come together to explore the efficacy of bringing authentic scientific research experiences, such as the ones in which scientists engage in their laboratories, into the arena of the public school classroom. The classroom provided the collaborative research context for the classroom teacher, research scientist, graduate student, and science education researcher to investigate the effects of engaging classroom learners in authentic research experiences as scientific researchers who investigate an authentic scientific problem; that is, a problem without a "known" solution. Unlike "guided inquiry," authentic scientific research implies that learners approach the educational setting knowing that there is no "right answer" to the solution of the problem; and that learners, teacher, and research scientist collaboratively investigate the solution to the scientific problem within the context of the classroom rather than the scientist's laboratory. Adjustments are made to methodologies and materials to better fit the classroom context, but data collection, analysis, and synthesis occur that result in discoveries valued by the community of scientists investigating similar problems in their laboratories.

The classroom learning environment, which includes public school learners as scientists and the teacher as research mentor, provides the rich context for research not only for the scientist and his team of scientific researchers. The classroom context also allows for the science education researcher and graduate student mentor to ask questions about the learning environment associated with authentic scientific inquiry, the types of discourse in which students engage, and the attitudes of the teacher who engages her learners in the process, respectively. Of high interest to all, of course, is the identification of unique student learning outcomes occurring as a result of the authentic research experience as compared with the science learning outcomes associated with guided inquiry settings.

\section{Implementation in the ITS Center}

For every two-year cycle, the ITS Center actively recruits university-based scientists and science educators, secondary teachers, and graduate students to form the collaborative teams. Teachers can earn 12 hours of graduate credit for a certificate from the ITS Center and/or towards a degree by completing the two summer sessions.

Following the pattern of the LRC, all participants come to the university campus for three weeks for the first summer session. Within the structure of two graduate courses, ITS participants from university and public school communities have options to form expert research teams who collaboratively investigate a common research problem. General topics for teams and university faculty to lead them are identified in the months preceding the first summer session. When teachers begin the first summer session, they can select one team to join. Past teams have investigated topics such as:

- landscape ecology and conservation,

- genomics research involving the plant species, Arabidopsis,

- visualizing biodiversity,

- energy equilibrium, conservation, \& conversion in material science, and

- human and ecological risk assessment.

Proceedings of the 2005 American Society for Engineering Education Annual Conference \& Exposition Copyright (C) 2005, American Society for Engineering Education 
Some time is included for instruction on pedagogy and IT, though most of the time is dedicated to collaborative work within project teams and to each teacher participant developing an Instructional Framework (IF). As described in the LRC, teachers implement their IFs in their classrooms over the next year.

Teachers who implement their IFs are allowed to return for the next summer session, which is also for three weeks on campus and within the structure of two graduate courses. Collaborative teams continue their work with further instruction as needed. Teacher participants develop their Research Plan (RP) to evaluate the efficacy of their IF. The teachers implement their RPs over the next school year, followed by a dissemination of their work. Campus Resource Persons (CRPs), who are graduate assistants with the ITS Center, are available to mentor and assist teachers remotely. As further motivation to complete this phase of the LRC, teachers receive a \$500 stipend upon completing their data collection and another \$500 stipend when they write a paper presenting their results for a conference.

The first cohort began in the summer of 2001 with 74 teacher-participants, 56 of which returned for the next summer session in 2002. The second cohort began in the summer of 2003 with 64 teachers and graduate student participants, 51 of which returned in 2004 . This cohort has just completed their second year of classroom implementation this spring (2005). Individuals in each cohort joined research scientists doing collaborative research in scientific teams, 10 university education researchers, and 20 graduate student mentors in the two years of activities embedded in the structure of the LRC professional development sequence.

\section{Results for Teacher and Faculty Participants}

Having described the LRC and its implementation in the ITS Center, two questions are addressed. First, how and to what extent have teachers implemented in their classrooms what they have learned in their summer program experience? This is answered with self-reports of

teachers via multiple surveys ${ }^{10,16}$ as to whether or not they have implemented their work and records of publications based on their research.

\section{Teacher Participants in Cohort I}

For Cohort I, 24 participants (43\%) out of 56 total in the second summer session completed the entire program and presented at a conference. Participants had the opportunity to submit inprogress reports or results of their RP at the annual meeting of the Southwest-Association for the Education of Teachers of Science conference held in 2003. Eighteen proposals were accepted for poster presentation, typically with multiple, collaborating presenters. All presenters were actively involved in educational activities (see Figure 2). It is not known how many participants did not attempt to present but had partially or fully implemented their IF and RP.

To examine teacher attitudes toward the ITS Center, the evaluation team conducted a survey in 2003. K-12 teachers that participated in the second summer session rated their overall satisfaction with the ITS Center experience at 3.48 on average (highest rating $=4, \mathrm{~N}=23$ ). K-12 
teachers were also asked what level of confidence they had in implementing their IF and rated their confidence at 2.65 on average (highest rating $=3, \mathrm{~N}=23$ ).

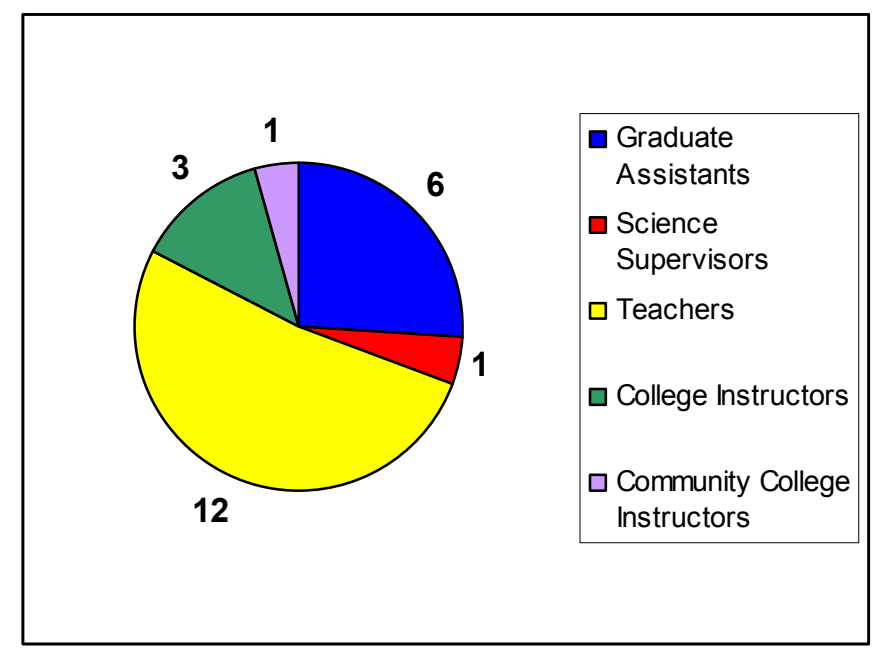

\section{Figure 2: ITS Center Presenters at the SW-AETS Conference}

\section{Teacher Participants in Cohort II}

For Cohort II, a total of 64 new participants designed their IFs during the first summer session in 2003 to be implemented in the 2003-2004 school year. A survey of Cohort II participants in Spring, 2004 indicated their progress in executing their implementation plans. Of 52 participants who responded, 51 reported either completing or continuing to carry out their implementation plan. The one who had not implemented a plan indicated that students had volunteered to participate, but did not follow through and actually participate although materials and procedures were ready. Also, of the 52 responders, 44 were able to identify tangible products students made based on what they learned. In a separate survey of the same participants in the same time period, 47 of 51 participants responded that they could identify specific items in their implementation plan they would modify and improve before implementing it again.

With respect to the students reached by these efforts, 48 of the participants targeted a K-12 or college level classroom situation in their IF and in total reported reaching approximately 2450 students. Demographics of the students reached by these collective outreach efforts by ethnicity and gender are found in Figure 3 and Figure 4, respectively. The figures show that ITS participants are reaching students who are in underrepresented groups in science. 


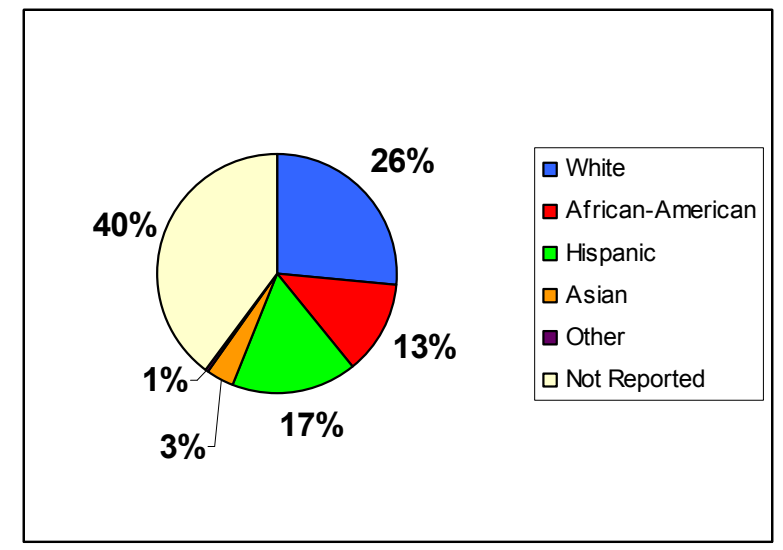

Figure 3: Ethnicity of students reached by Cohort II Participants

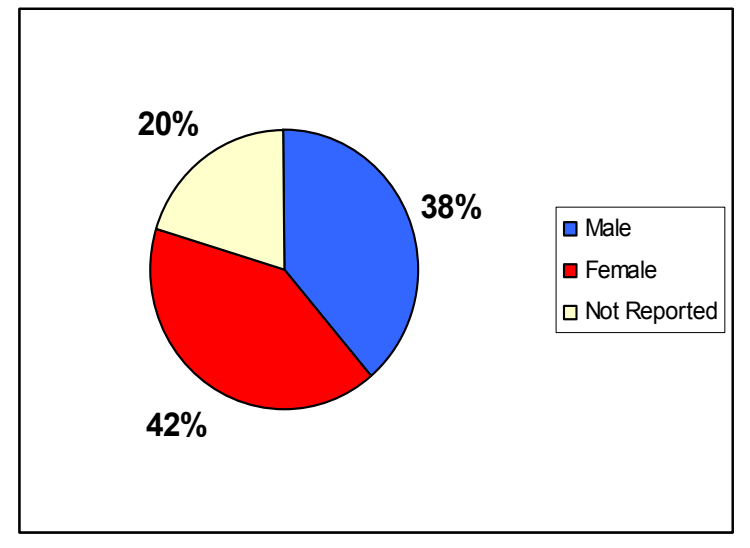

Figure 4: Gender of students reached by Cohort II Participants

Cohort II participants developed RPs during the second summer session in 2004. As these activities are still ongoing at the time of this writing, data are not available on implementation of RPs or overall satisfaction of Cohort II participants with the ITS Center experience.

\section{Faculty Participants in the ITS Center}

A total of 10 College of Education research faculty, 30 scientists, and 4 engineers participated during the past four years in the design and implementation of the ITS Center's professional development program. Nine of the scientists and two of the engineers are planning to participate in the next two years of the ITS Center's research and professional development activities (Cohort III). In general, the following monetary incentives are provided for faculty participation:

- Up to 2 months of summer salary support for each of up to 3 faculty members working together on a team. This salary support may be transferred to one or more graduate students who will work directly with the ITS Center activity and research planning and implementation.

- Travel support for presenting an ITS-related paper at a professional conference of the faculty member's choosing. Again, this may be transferred to a graduate student who participated in ITS work.

- Support for materials and supplies needed for the summer session. This may include materials that are consumed during the summer session, or supplies needed by participants to continue their work with their students when they return to their instructional settings.

While these may be regarded as relatively frugal financial incentives, many faculty have expressed the following advantages to participation to the ITS Center evaluation team ${ }^{12}$ as greater benefits of working in the interdisciplinary ITS Center environment: 
- Opportunities to work with faculty in other departments who have related research interests. For example, biological agricultural engineers, who are housed in the College of Agriculture at Texas A\&M University, forged research connections with civil engineers, who are housed in the College of Engineering.

- Opportunities to engage their graduate students in teaching-related design and research related to their scientific research. This educational development and research experience added to a science or engineering graduate students' resume increases their marketability.

- Opportunities to increase their skills in addressing with quality the education components now required by many of the funding agencies for their science and engineering grant proposals.

In addition, 28 of the science and engineering faculty participants reported significant positive changes after participation with the ITS Center in their understanding of the needs of pre-college teachers in order to be adequately prepared to teach science and mathematics; in their knowledge of what learning means and how people learn; in their knowledge of how to assess the extent to which learning has occurred; in their knowledge of specific Information Technology used for modeling, visualization, or interaction with complex data sets; and in their applications of learning and teaching theory in their own classrooms in teaching undergraduates or teaching precollege teachers.

\section{Application of the LRC to Engineering in K-12 Education}

In light of the outcomes for both K-12 teachers and university faculty, applying the LRC to engineering K-12 outreach is considered. It should also be noted that the LRC is not foreign to engineering as four engineering faculty members have already participated in the ITS Center's activities (two civil engineering, two biological and agricultural engineering, and one petroleum engineering).

The major changes to the LRC model if applied to K-12 engineering outreach would stem from the difference between science and engineering. As opposed to scientific endeavors, engineering is focused on the design, execution, and evaluation of a product, process, or service. The LRC model is designed to give teachers a better sense of authentic science using IT, in part by having them engage in their own scientific activity through the investigation of IT and their own IF and the effect on their students. While the research aspect can be maintained when the LRC is applied to engineering, the focus for participants should be less on the scientific inquiry and more on the design aspect of creating an IF and any accompanying artifacts in the context of the team collaboration. Also, the emphasis on using IT in the classroom need not be a focus, as participants may create physical, electronic, or conceptual artifacts. Figure 5 is a LRC model modified for K-12 engineering outreach. IT follows essentially the same timeline and pattern as the original (Figure 1), but focuses on engineering design. 


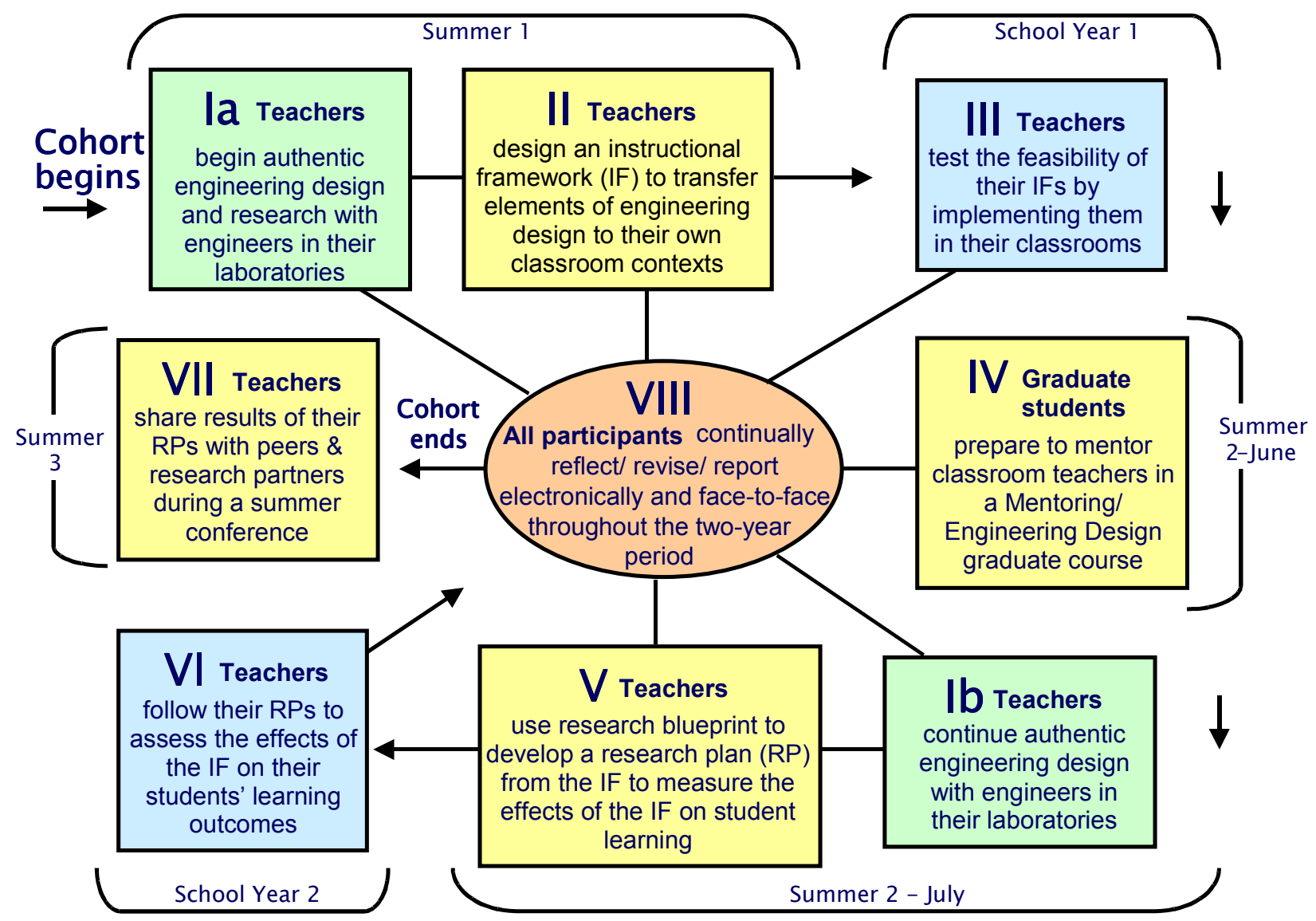

Figure 5: LRC Model Modified for K-12 Engineering Outreach

In this modified LRC model, participants will collaborate with engineering faculty and education specialists in an engineering design process to produce their own artifacts that will assist their students' learning. These artifacts may be physical items that demonstrate some aspect of engineering, software that is used to solve engineering problems, or a prototype for an engineering challenge (e.g., egg drop competitions). By engaging in this design process, both for the IF and for individual artifacts, in a collaborative environment, the K-12 teacher participants can learn what the field of engineering is about, what problems engineers address and how they address them, and how to bring those concepts back to their students.

\section{Summary}

While there are many methods for engineers to reach out to K-12 students, an advantage of professional development is that resources are spent on training teachers who can reach students year after year. The LRC, a model for professional development presented here, engages secondary school science teachers with scientists, mathematicians, engineers, science education researchers, and their graduate students to improve science teaching and learning through the use

Proceedings of the 2005 American Society for Engineering Education Annual Conference \& Exposition Copyright (C) 2005, American Society for Engineering Education 
of IT. The application of the LRC in the two year graduate credit program at the ITS Center is also described.

This paper set out to identify how and to what extent participant teachers have applied what they learned to the classroom and if there are benefits to faculty who participate. To answer the first question, data collected from Cohorts I and II indicate that participants have applied what they learned in the ITS Center program to their classroom setting. Survey results from participants in Cohort I indicated a high level of satisfaction with the program. Twenty-four participants in Cohort I completed the entire program which culminated in presenting their work at a regional conference. Though Cohort II is not complete at the time of this writing, 51 participants had progressed through the second summer session of the program and had reached approximately $2450 \mathrm{~K}-12$ students collectively. To answer the second question, university faculty who have been involved in the program as scientific experts reported positive outcomes as a result of the ITS Center program, including positive changes in their self-reported understanding of what learning means and how people learn and of how to assess the extent to which learning has occurred. Also, faculty reported that the ITS Center provided the means to collaborate with new colleagues.

Finally, a modified LRC model is presented that is more applicable to K-12 engineering outreach as it focuses on design, collaboration with engineers, and the creation of and interaction with artifacts beyond IT. In the ITS Center, the LRC for science has shown success in terms of teacher implementation of what they learned, positive faculty outcomes, and reaching a large body of students. This success, coupled with the small amount of modification that would be required to implement this model for engineering, highly recommend the LRC as a model for K12 engineering outreach.

\section{Acknowledgements}

This material is based on work supported by the National Science Foundation under Grant No. ESI-0083336.

\section{References}

1. J. D. Abbitt III and B. F. Carroll, "Aplied aerodynamics experience for secondary science teachers and students," Journal of Engineering Education, vol. 82, pp. 185-188, 1993.

2. ASEE. (2004) "Outreach Database - K-12 Program Search," American Society for Engineering Education Engineering K-12 Center. [Online]. Available http://www.engineeringk12.org/educators/making_engineers_cool/search.cfm

3. C. A. Chinn and B. A. Malhorta, "Epistemologically authentic inquiry in schools: A theoretical framework for evaluating inquiry tasks," Science Education, vol. 86, pp. 175-218, 2002.

4. J. L. deGrazia, "Engineering workshops for K-12 school teachers," in Proceedings of the Frontiers in Education Conference, pp. T1E-9 - T1E-14, 2001.

5. The Design-Based Research Collective, "Design-Based Research: An emerging paradigm for educational inquiry," Educational Researcher, vol. 32, pp. 5-8, 2003.

Proceedings of the 2005 American Society for Engineering Education Annual Conference \& Exposition Copyright (C) 2005, American Society for Engineering Education 
6. J. Douglas, E. Iversen, and C. Kalyandurg, (2004, December). Engineering in the K-12 classroom: An analysis of current practices \& guidelines for the future. American Society for Engineering Education EngineeringK12 Center. [Online]. Available: http://www.engineeringk12.org/Engineering_in the_K-12_Classroom.pdf.

7. A. M. Hoff, M. Barger, R. Gilbert, K. S. Rogers, J. D. Hickey, E. Roe, and B. McCullough, "Teaching problem solving to high school and community college students: A new approach," in Proceedings of the American Society for Engineering Education Annual Conference, 2002.

8. A. T. Jeffers, A. G. Safferman, and S. I. Safferman, "Understanding K-12 engineering outreach programs," Journal of Professional Issues in Engineering Education and Practice, vol. 130, pp. 95-108, 2004.

9. A. Kelly, "Design research in education: Yes, but is it methodological?," The Journal of the Learning Sciences, vol. 13, pp. 115-128, 2004.

10. G. Kulm and N. Eyyuboglu, (2003, June). ITS Center Internal Evaluation Report for Year Three. Information Technology in Science Center for Teaching and Learning at Texas A\&M University, College Station, TX. research report ITS-ER-2003. [Online]. Available: http://its.tamu.edu/downloads/ITS-ER-2003.pdf.

11. J. E. Miller and J. J. Rencis, "A university/public school parternship in K-6 engineering education," in the Proceedings of the American Society for Engineering Education Annual Conference, 2004.

12. J. Minstrell and R. Anderson, "ITS Center External Evaluation Report," Information Technology and Science Center for Teaching and Learning at Texas A\&M University, College Station, TX, (unpublished internal document), 2002.

13. J. R. Mountain and R. L. Wells, "Engaging K-12 students and teachers using competitive interactive design," in Proceedings of the Frontiers in Education Conference, 2002.

14. R. J. Noeth, T. Cruce, and M. T. Harmston, "Maintaining a strong engineering workforce," American College Testing Inc., Iowa City, IA 2003.

15. S. Schreiner and J. Burns, "Disseminating biomedical engineering concepts to 8th-12th grade teachers," in Proceedings for the American Society for Engineering Education Annual Conference, 2001.

16. C. L. Stuessy, "From intent to authentic inquiry: Analysis of participant implementations," Information Technology in Science Center for Teaching and Learning, College Station, TX, PDF April 2003.

17. L. W. Zachary, J. M. Sharp, and B. M. Adams, "Engineering connections: Teaching engineering mechanics to K-12 teachers," in the Proceedings of the American Society for Engineering Education, 2000.

18. M. S. Zarske, J. F. Sullivan, L. E. Carlson, and J. L. Yowell, "Teachers teaching teachers: Linking K-12 engineering curricula with teacher professional development," in the Proceedings of the American Society for Engineering Education Annual Conference, 2004.

GEORGE M. NICKLES III is a post-doc research associate in the Information Technology in Science (ITS) Center for Teaching and Learning at Texas A\&M University. He earned his PhD in Industrial and Systems Engineering at Georgia Tech in 2004 with an emphasis in Human-Integrated Systems. His research interests include cognitive engineering, educational technology, and evaluation of education.

JANE F. SCHIELACK is a Professor of Mathematics at Texas A\&M University and Co-PI and Project Director of the Information Technology in Science (ITS) Center for Teaching and Learning. She leads the development of strategies and learning experiences to enhance teacher preparation and teacher professional development through creation of science and mathematics education specialists with advanced degrees.

CAROL STUESSY is an Associate Professor in the Department of Teaching, Learning, and Culture at Texas A\&M University. She earned her PhD in Science Education at the Ohio State University in 1985. A science educator specializing in the design of innovative science learning environments, Dr. Stuessy models innovative learning environments in public school and undergraduate science classrooms.

Proceedings of the 2005 American Society for Engineering Education Annual Conference \& Exposition Copyright $\left({ }_{0}\right.$ 2005, American Society for Engineering Education 